\title{
O Processo de Desenvolvimento de Produtos de Moda baseado no Design Thinking: um estudo de caso
}

\author{
The Process of Development of Fashion Products based on Design Thinking: a case study
}

\author{
CARDOSO, Marina Xavier; Pós-graduanda em Gestão Estratégica de Design; \\ Universidade Estadual de Londrina \\ marinaxcardoso@gmail.com
}

\author{
DEMARCHI, Ana Paula P.; Dra. Engenharia e Gestão do Conhecimento; \\ Universidade Estadual de Londrina \\ perfeto@sercomtel.com.br
}

\begin{abstract}
RESUMO
O presente artigo trata do processo de desenvolvimento de produtos de moda, um processo que está diante de mudanças velozes e constantes troca de informações. Perante esse cenário, uma abordagem se destaca: o design thinking. Com isso, este artigo pretende estruturar e sugerir melhorias ao processo de desenvolvimento de produtos de uma indústria de confecção, baseado no Design Thinking. Para tanto foi feito o diagnóstico do processo de desenvolvimento de produtos e uma proposta de intervenção com o intuito de fortalecer os pontos fracos identificados por meio da análise realizada.
\end{abstract}

Palavras Chave: Processo de desenvolvimento de produtos; Indústria de confecção; Design thinking.

\begin{abstract}
This article discusses the process of development of fashion products, a process that is rapidly changing face and constant exchange of information. Given this scenario, one approach stands out: design thinking. Therefore, this article aims to structure and suggest improvements to the development process of a product manufacturing industry, based on Design Thinking. For that was diagnosed in the process of product development and a proposal for intervention in order to strengthen the weaknesses identified by the analysis performed.
\end{abstract}

Keywords: Development process products; Clothing industry; Design thinking.

\section{INTRODUÇÃO}

Atualmente, o mercado vem passando por inúmeras mudanças, o Brasil, por exemplo, vive um grande crescimento econômico. Diante deste novo cenário, o consumidor mudou seu comportamento e suas expectativas perante os bens de consumo, ele está mais exigente e busca não apenas um produto funcional, mas também uma grande experiência. Agora para atender as novas necessidades dos consumidores, os negócios necessitam adaptar-se às mudanças e renovar suas estratégias.

No mercado da moda a situação também não é diferente, o ambiente industrial de confeç̧ão possui inúmeros profissionais, uma série de limitações e troca de informações. O mercado conforme afirma Montemezzo (2007) "[..] requer velocidade e dinamismo na interação das inúmeras informações da cadeia têxtil".

Emídio (2006) complementa que no ambiente da indústria de confecção, a dinâmica da moda exige um designer que se concilie com o cenário de mudanças velozes, incorporando conceitos e 
posicionamentos gerenciais na sua prática profissional.

As empresas têm buscado continuamente processos mais eficientes que agilizem seus processos de decisão, normalmente estes alteram suas estruturas organizacionais, levando-os a adotar novos modelos de gestão. "Desta forma, a gestão do design passa a ser essencial para as empresas que pretendem se destacar neste cenário de pressão competitiva e inovação continuada que caracteriza a indústria da moda". (Montemezzo, 2007, p.7)

Perante esse cenário, uma abordagem se destaca: o design thinking, que tem como definição mais popular, segundo Martin (2009), pensar como um designer o faria. O mesmo autor afirma que o design thinking é uma fonte de vantagem competitiva e é considerado o fator essencial para as organizações obterem inovação.

Frente a este contexto resta a questão: De que forma a gestão de design e a gestão do conhecimento podem contribuir ao processo de desenvolvimento de produtos de moda?

No intuito de respondê-la, este artigo pretende estruturar e sugerir melhorias ao processo de desenvolvimento de produtos de uma indústria de confecção, baseado no Design Thinking. Para tanto será necessário diagnosticar como realmente acontece o desenvolvimento de produtos e evidenciar as habilidades dos membros envolvidos no processo para depois propor um processo considerando as habilidades necessárias.

\section{$O$ processo de desenvolvimento de produtos de moda}

Para Rozenfeld et al (2006) o processo de desenvolvimento de produtos (PDP) trata-se de um conjunto de atividades que busca identificar as oportunidades do mercado e aplicá-las nas especificações de um produto. Este, por sua vez, deve atender tanto às expectatitas do mercado quanto da empresa e respeitar os requisitos legais, às restrições tecnológicas, de custo e qualidade.

Segundo Montemezzo (2003) o desenvolvimento de produtos de moda destina-se a concepção de produtos orientados para o mercado, com obsolescência programada e que além da função de abrigo e proteção devem contemplar os valores simbólicos dos códigos estéticos vigentes. A mesma autora sinaliza os pontos cruciais para o desenvolvimento de produtos de moda como os seguintes:

- flexibilidade e agilidade no tratamento das suas metodologias de projeto, considerando o dinamismo e a velocidade que envolvem o desenvolvimento de produtos nesta área;

- imersão profunda no contexto comportamental do usuário/consumidor, tendo em vista o valor emocional que se vincula ao produto de moda;

- decodificação das tendências estéticas e socioculturais vigentes em códigos de linguagem que se relacionem com o universo do usuário/consumidor, estabelecendo, com este, um canal de comunicação;

- bom pensamento de usabilidade já que há uma interação generalizada e direta do produto com o corpo humano, como uma segunda pele.

A representação gráfica ou textual de um PDP ideal como um modelo referencial, segundo Rozenfeld et al (2006), pode ser uma boa alternativa. A partir de um modelo de referência, uma empresa pode definir seu modelo específico de acordo com suas necessidades e particularidades. Assim, ele se torna um manual de procedimentos para o desenvolvimento de produtos e constitui-se em um repositório de melhores práticas.

Existem diversos modelos de referências para o PDP, entretanto para a realização deste trabalho serão estudados dois modelos: o primeiro, proposto por Montemezzo (2003) e o segundo, proposto por Jordan (2004).

O primeiro modelo foi originado da síntese das reflexões de vários autores do design projetual e complementado com a realidade profissional do designer de moda. O modelo possui seis etapas apresentadas na figura 1 , abaixo:

Figura 1 - Desenvolvimento de produtos de moda/vestuário. 
O Processo de Desenvolvimento de Produtos de Moda ... no Design Thinking: um estudo de caso

\begin{tabular}{|c|c|}
\hline Etapas & Ações \\
\hline \multirow[t]{5}{*}{ Planejamento } & Percepção do mercado e descoberta de oportunidades \\
\hline & Análises / expectativas e histórico comercial da empresa \\
\hline & Idéias p/produtos/Identificação do problema de design \\
\hline & $\begin{array}{l}\text { Definição de estratégias de marketing, desenvolvimento, produção, distribuição e } \\
\text { vendas. }\end{array}$ \\
\hline & Definição do cronograma \\
\hline \multirow{4}{*}{$\begin{array}{l}\text { Especificação do } \\
\text { projeto }\end{array}$} & Análise e definição do problema de design (diretrizes) \\
\hline & Síntese do Universo do consumidor (físico e psicológico) \\
\hline & Pesquisa de conteúdo de moda (tendências) \\
\hline & Delimitação do projeto (objetivos) \\
\hline \multirow{2}{*}{$\begin{array}{c}\text { Delimitação } \\
\text { Conceitual }\end{array}$} & Geração de conceitos e definição do Conceito Gerador \\
\hline & Definição de princípios funcionais e de estilo \\
\hline \multirow[t]{2}{*}{$\begin{array}{l}\text { Geração de } \\
\text { alternativas }\end{array}$} & $\begin{array}{l}\text { Geração de alternativas de solução do problema } \\
\text { (esboços/desenhos, estudos de modelos). }\end{array}$ \\
\hline & Definições de configuração, materiais e tecnologias \\
\hline \multirow{5}{*}{$\begin{array}{l}\text { Avaliação e } \\
\text { Elaboração }\end{array}$} & Seleção da(s) melhor (es) alternativa(s) \\
\hline & Detalhamento de configuração (desenho técnico) \\
\hline & Desenvolvimento de ficha técnica, modelagem e protótipo \\
\hline & Testes ergonômicos e de usabilidade \\
\hline & Correções/adequações \\
\hline \multirow[t]{9}{*}{ Realização } & Avaliações técnicas e comerciais apuradas \\
\hline & Correções/adequações \\
\hline & Graduação da modelagem \\
\hline & $\begin{array}{l}\text { Confecção de Ficha técnica definitiva e Peça piloto (aprovação técnica e comercial } \\
d o(s) \text { produto(s)) }\end{array}$ \\
\hline & Aquisição de matéria prima e aviamentos \\
\hline & Orientação dos setores de produção e vendas \\
\hline & Definição de embalagens e material de divulgação \\
\hline & Produção \\
\hline & Lançamento do(s) produto(s) \\
\hline
\end{tabular}

Fonte: Montemezzo (2003)

Como podemos ver, o diagrama discrimina as principais ações realizadas no PDP de moda e destacadas em cinza estão as ações em que o designer está diretamente envolvido. Porém, o mesmo deve estar envolvido em todas as fases do processo, pois isso irá influenciar suas decisões na configuração do produto assim como poderão garantir a qualidade do projeto. Assim, sob um raciocínio projetual consciente e organizado é possível encontrar uma melhor solução para o projeto, cujo sucesso está vinculado às orientações definidas na etapa de planejamento.

No PDP de moda existem ferramentas que estão inseridas no processo, entre elas está o Painel Semântico, painel que traduz visualmente o conceito da coleção, é defendido por Montemezzo (2007) como uma boa ferramenta de comunicação entre os setores de criação, desenvolvimento e comercial de uma empresa. Além de auxiliar na organização dos fatores relevantes para o desenvolvimento de um conjunto de produtos, a coleção. Outra ferramenta importante são as fichas-sínteses, por meio da qual se faz o registro e avaliação da conduta projetual, ela permite uma visão panorâmica do projeto e facilita a comunicação no trabalho em equipe, que diante do contexto da confecção, trata-se de uma cadeia produtiva bastante fragmentada. Vale destacar que a ficha técnica é outra ferramenta essencial para uma boa comunicação entre os setores de criação, desenvolvimento e comercial de uma empresa; evitando perda de informações durante a produção.

O modelo proposto por Jordan (2004) foi desenvolvido para o PDP na indústria têxtil/vestuário destinado a empresas que tenham marca própria. A autora salienta que este modelo destina-se: 
- como informação para as empresas ou profissionais da área que buscam a profissionalização do desenvolvimento de produtos,

- como aproximação de uma visão sistêmica do desenvolvimento de produtos de vestuário utilizando os conceitos da Engenharia de Produção,

- como ferramenta para redução do tempo de desenvolvimento e sucesso do produto.

Este modelo possui três macro-fases: pré-desenvolvimento, desenvolvimento e pósdesenvolvimento.

A macrofase de pré-desenvolvimento abrange três etapas:

- Avaliação preliminar do mercado: busca de informações sobre as necessidades dos clientes por meio de dados primários e secundários, destacando as oportunidades de mercado e seu potencial. Nesta etapa é muito importante o estudo do estilo de vida dos consumidores do segmento que se pretende atender;

- Diretrizes de novos produtos: planejamento em relação ao mix de produtos e linhas (amplitude, profundidade, consistência), ciclo de vida (longo, médio ou curto), cronograma de lançamento e execução do desenvolvimento em si;

- Geração e triagem de idéias e geração do conceito: coleta de elementos que possam ser usados como referência para a coleção, como cores, formas, texturas e produtos similares.

A macrofase de desenvolvimento é constituída por seis etapas:

- Desenvolvimento do conceito da coleção: as idéias da etapa anterior são convertidas em uma versão detalhada com os elementos mais significativos para o consumidor. O conceito deve atender as necessidades do consumidor e possuir um diferencial em relação a outros existentes no mercado;

- Desenvolvimento do projeto dos produtos da coleção: criação dos modelos por meio de desenhos dos produtos e organização das amostras de tecidos e aviamentos que poderão ser utilizados;

- Especificação dos produtos: nesta fase é elaborada a ficha técnica dos produtos com informações desde a matéria-prima até especificações de costura.

- Modelagem e produção das amostras: são feitas as modelagens e ajustes necessários, e a confecção da peça piloto.

- Preparação para a produção: por meio das peças piloto e fichas técnicas aprovadas são feitos estudos de métodos e processos para a produção.

- Manufatura das amostras: são produzidas as peças de mostruário que seguem para os representantes ou para postos de venda. Esta fase serve de base para ajustes dos métodos e processo de produção.

Já a macrofase de pós-desenvolvimento não possuiu etapas, nesta fase são feitas a avaliação do processo de desenvolvimento e o acompanhamento do produto no mercado, para tanto são feitas comparações entre as métricas planejadas no pré-desenvolvimento e as obtidas, como por exemplo: o percentual de vendas, tempo de lançamento e custos de desenvolvimento e desempenho, entre outros. Esta fase compreende ainda o registro de lições aprendidas, onde são feitos os registros dos processos (facilidades e dificuldades) que são arquivados em dossiês para consultas futuras. Assim o modelo de desenvolvimento deve ser aperfeiçoado a cada projeto.

$O$ modelo propõem que sejam feitos gates - pontos de decisão entre as fases - esses gates encontram-se nos pontos críticos do processo e garantem o controle da qualidade do PDP, evitando assim que ao final de cada etapa o produto não atenda as especificações do início do processo. De acordo com Jordan (2004), os documentos referentes aos gates devem ser elaborados pela equipe de trabalho, ter um objetivo definido e ser de fácil preenchimento. Quando os gates são aprovados o projeto pode seguir para a próxima fase.

Os documentos referentes aos gates, sugeridos pela autora são: Documento de Conceito de Coleção: consiste num resumo do conceito justificando os elementos utilizados, elaborado pelo designer de moda; Documento de Desenvolvimento de Fornecedor: elaborado pelo setor de compras; Aprovação dos Desenhos da Coleção: consiste do próprio desenho que será aprovado com um visto da equipe responsável pela aprovação; Aprovação das peças piloto: consiste de aprovação com um visto na ficha técnica num campo apropriado a esta validação e Aprovação da Ficha Técnica: visto na ficha técnica do produto. Também é proposto uma Matriz de Responsabilidades adaptada para a indústria 
O Processo de Desenvolvimento de Produtos de Moda ... no Design Thinking: um estudo de caso

têxtil, apresentada na figura 2 abaixo, nela estão contidos os setores envolvidos e relacionados às fases do PDP. Por meio dela pode-se verificar como cada setor participa do processo, sendo como responsável (R), participante (P) ou apenas informado (I).

Figura 2: Matriz de responsabilidades

\begin{tabular}{|c|c|c|c|c|c|c|c|}
\hline Fases do PDP Setores envolvidos & 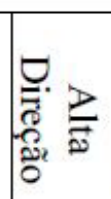 & 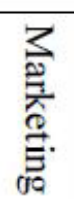 & 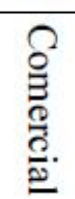 & 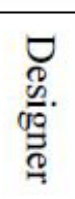 & $\frac{\Omega}{\tilde{c}}$ & 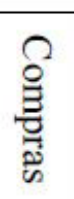 & $\widetilde{\partial}$ \\
\hline Avaliação preliminar do mercado & $\mathrm{R}$ & $\mathrm{P}$ & $\mathrm{P}$ & $\mathrm{P}$ & & & \\
\hline Diretrizes de novos produtos & $\mathrm{R}$ & $\mathrm{P}$ & $\mathrm{P}$ & $\mathrm{P}$ & I & & I \\
\hline $\begin{array}{l}\text { Geração e triagem de idéias, e geração de } \\
\text { Conceito }\end{array}$ & I & $\mathrm{P}$ & $\mathrm{P}$ & $\mathrm{R}$ & I & & \\
\hline Análise de viabilidade (GATE 1) & $\mathrm{R}$ & $\mathrm{P}$ & $\mathrm{P}$ & $\mathrm{P}$ & $\mathrm{I}$ & & \\
\hline Desenvolvimento do conceito da coleção & & $\mathrm{P}$ & $\mathrm{I}$ & $\mathrm{R}$ & & $\mathrm{I}$ & \\
\hline Aprovação do conceito (GATE 2) & I & I & $\mathrm{I}$ & $\mathrm{P}$ & I & $\mathrm{R}$ & \\
\hline Desenvolvimento do projeto do Produto & & $\mathrm{I}$ & & $\mathrm{R}$ & $\mathrm{I}$ & & $\mathrm{I}$ \\
\hline Aprovação (GATE 3) & $P$ & $\mathrm{P}$ & $\mathrm{P}$ & $\mathrm{R}$ & $\mathrm{P}$ & I & $\mathrm{P}$ \\
\hline Especificação do produto & & & & $\mathrm{R}$ & & I & $\mathrm{P}$ \\
\hline Modelagem e produção das amostras & $\mathrm{I}$ & & & $\mathrm{P}$ & & & $\mathrm{R}$ \\
\hline Aprovação dos pilotos (GATE 4) & $P$ & $\mathrm{P}$ & $\mathrm{R}$ & $\mathrm{P}$ & I & I & I \\
\hline Preparação para a produção & & & & I & I & $\mathrm{P}$ & $\mathrm{R}$ \\
\hline Manufatura das amostras & & & & $\mathrm{P}$ & $\mathrm{I}$ & & $\mathrm{R}$ \\
\hline Avaliação (GATE 5) & & & & & & & $\mathrm{R}$ \\
\hline Dossiê da Coleção & & & & $\mathrm{R}$ & & & \\
\hline
\end{tabular}

Fonte: Jordan (2004)

A figura 3, abaixo, apresenta um modelo de fluxograma para o PDP proposto por Jordan (2004), nele estão descritas as fases do processo, os objetivos, setores envolvidos e documentação gerada a cada etapa; assim como a localização dos gates, pontos de decisão, descritos anteriormente.

Figura 3: Modelo de fluxograma do PDP. 


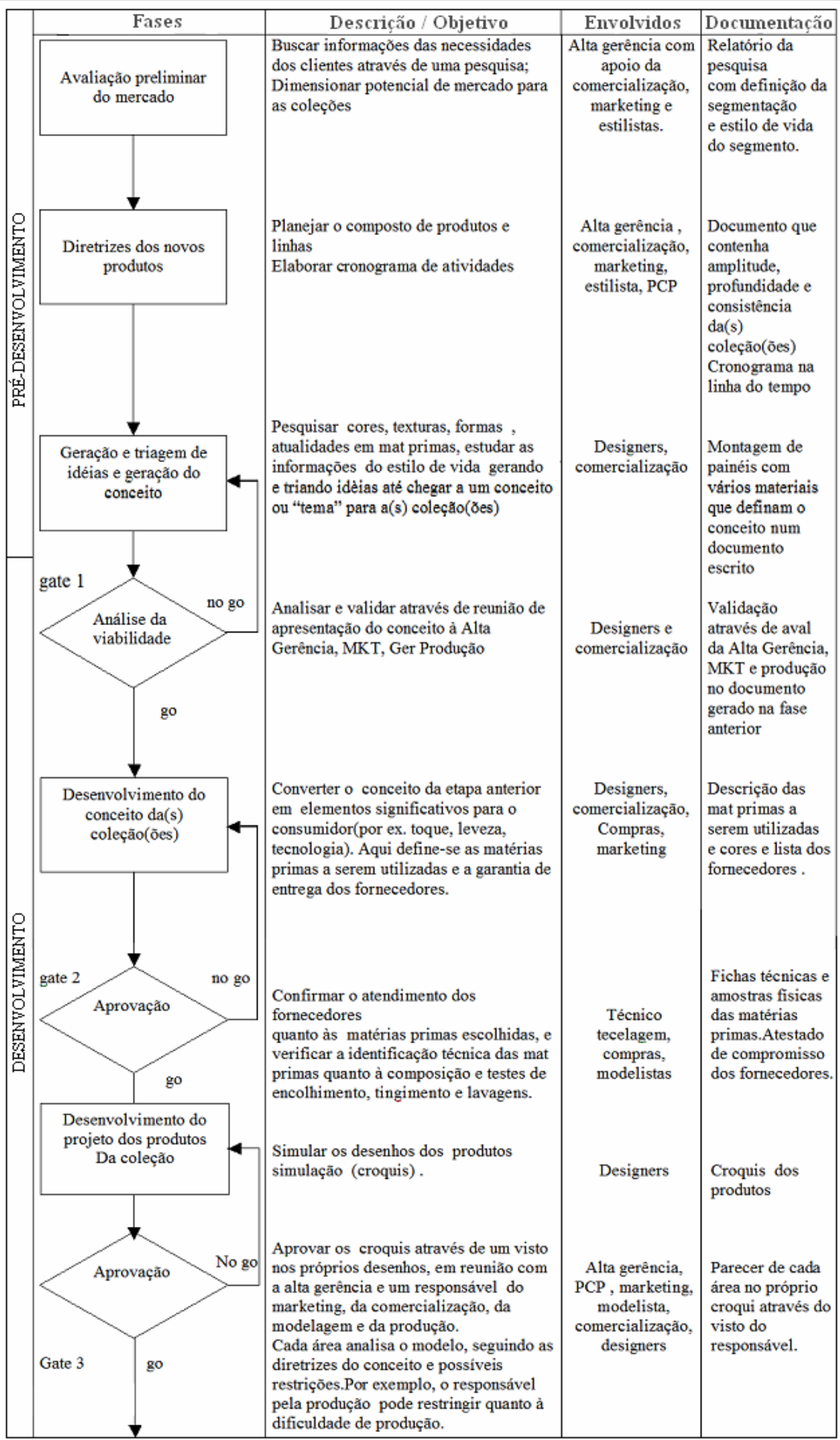


O Processo de Desenvolvimento de Produtos de Moda ... no Design Thinking: um estudo de caso

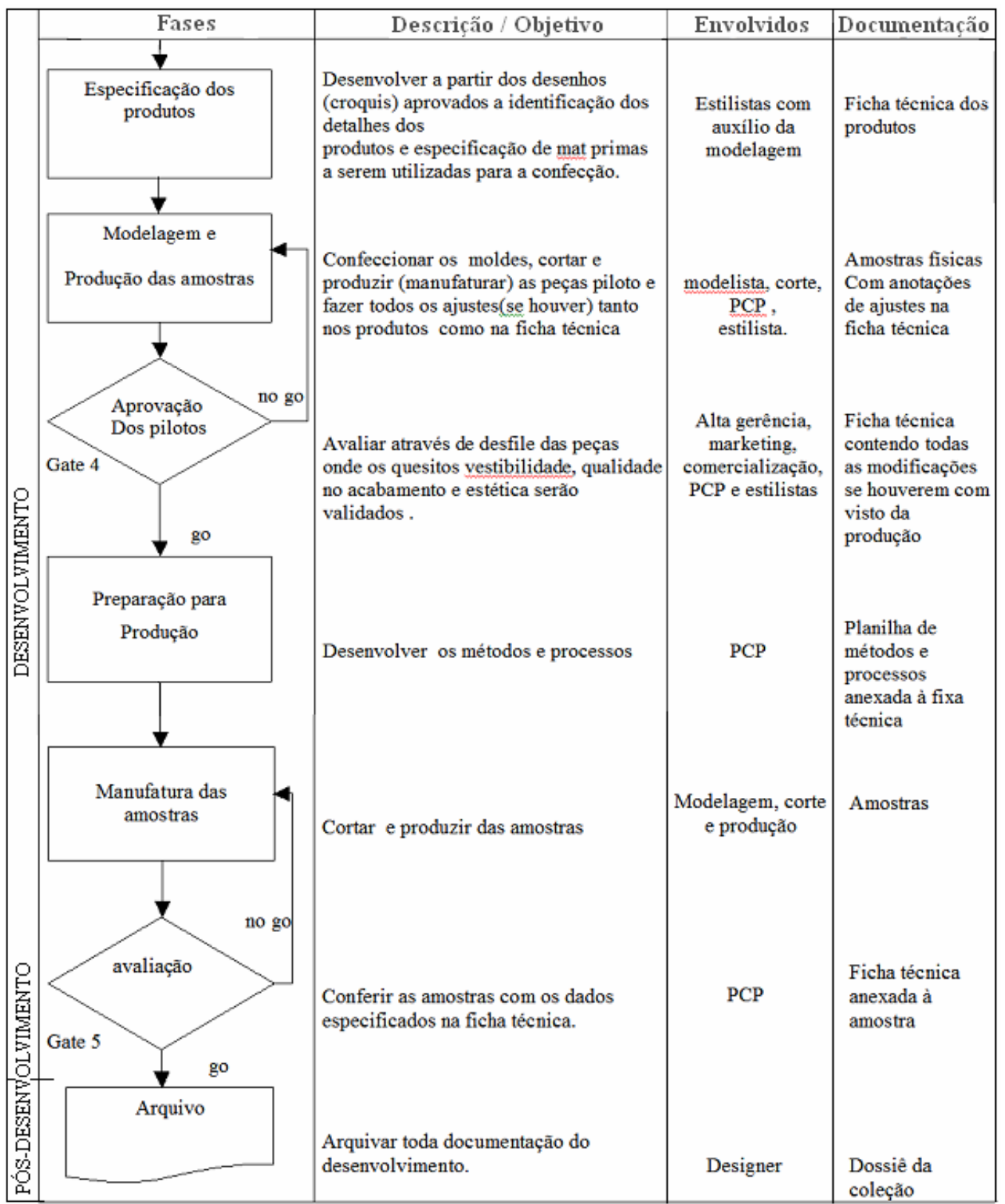

Fonte Jordan (2004)

Este artigo utilizará como base o modelo de fluxograma acima. No entanto este modelo possui uma estrutura bastante rígida e linear, diferentemente de como funciona o PDP atualmente nas empresas. Devido ao contexto atual, onde a troca de informações é muito rápida, o processo necessita ser bastante flexível e capaz de se adaptar às mudanças.

\section{Design Thinking}

De acordo com Demarchi (2011), design thinking não deve ser considerado um novo conceito ou uma nova prática, ele está presente, mesmo que de maneira inconsciente, desde que existe o design.

Para Cooper, Junginger, Lockwood (2006, apud DEMARCHI, 2011, p. 129) design thinking tem uma definição imprecisa, dentre as encontradas no dicionário estão: thinking of (pensar em), thinking about (pensar sobre), e thinking through (pensar por meio de), a autora afirma que ele abrange essas três definições. As organizações estão mais habituadas com as duas primeiras definições, porém surge uma nova forma de aplicar o design thinking: pensar por meio do design, ou seja, pensar como os 
designers fazem.

Segundo a mesma autora, design thinking abrange a habilidade de visualizar rapidamente problemas e conceitos, o desenvolvimento de cenários baseados em pessoas e a construção de estratégias de negócio a partir dos métodos de pesquisa dos designers.

A cultura do design thinking, conforme afirma Demarchi (2011), encoraja a confecção de protótipos, que pode ser considerada uma maneira de pensar visualmente. Com isso, o design thinking reduz o medo de falhar e encoraja a máxima absorção e participação dos indivíduos no processo de resolução de problemas.

Lockwood (2009) define design thinking como um processo de inovação com foco no ser humano, onde se destacam a observação, colaboração, aprendizado rápido, visualização de ideias, protótipo rápido de conceitos e a análise do concorrente, que resultam numa forte influência na inovação e na estratégia do negócio.

Para Brown (2010), design thinking tem início com as habilidades que os designers adquiriram com o passar do tempo, entre elas estão a habilidade de alinhar as necessidades dos consumidores com os recursos tecnológicos disponíveis dentro da organização, a intuição, a habilidade de reconhecer padrões, construir ideias que tenham significado emocional e funcional, habilidade de expressar ideias de maneira diferente, não usando apenas palavras ou símbolos. Dentre as habilidades do design thinker, de acordo com o mesmo autor, está também a habilidade de trabalhar de forma interdisciplinar. É importante saber diferenciar um trabalho em um grupo interdisciplinar e um grupo multidisciplinar, neste ultimo cada integrante tende a defender sua própria especialidade técnica, prejudicando assim o projeto. Já em um grupo interdisciplinar existe uma ideia coletiva e todos do grupo são responsáveis por ela.

O autor Lockwood (2009) define cinco aspectos-chave do design thinking:

- adquirir um profundo entendimento do consumidor por meio da pesquisa de campo. Neste aspecto, torna-se importante o uso da abordagem empática, que contribuirá tanto como fonte de inspiração quanto para identificar nos consumidores necessidades desarticuladas. Para tanto, usa-se a observação e métodos etnográficos.

- formar grupos multidisciplinares, que trabalhem de forma interdisciplinar.

- capacidade de acelerar o aprendizado por meio da visualização, experimentação e criação de protótipos rápidos.

- habilidade de gerar visualizações de conceitos.

- integrar a análise do negócio durante o processo e não no seu término, utilizando-a como forma de limitar a criatividade. Desta maneira há o pensamento integrativo, onde há a combinação da criatividade com os aspectos estratégicos tradicionais, possibilitando um ponto de vista mais completo.

A incorporação do design thinking em uma organização não é uma tarefa simples, conforme Brown (2010), visto que nossa cultura nos impõe um pensamento lógico e dedutivo, onde somos treinados a receber informações, analisar e convergir em uma única resposta. Caminhando para o lado oposto do design thinking, que propõe o pensamento abdutivo. Para explicar melhor como funciona o processo de design baseado no design thinking, segue o tópico abaixo.

\section{Processo de design baseado no design thinking}

Demarchi, Fornasier e Martins (2012) afirmam que o processo de gestão de design baseado no design thinking leva a abordagem do designer aos diversos níveis na organização, mudando a maneira de fazer negócio e tornado-se uma ferramenta para a diferenciação. O processo de design é composto por uma série de métodos reunidos, que são adequados de acordo com cada projeto. Este processo é bastante dinâmico e não é linear, possui muitos ciclos de feedback, os quais permitem além de acomodar os insights que ocorrem em cada estágio do processo, também possibilitam manter a natureza interativa do design.

Os métodos usados no processo são definidos, por Jones (1978), como ensaios que permitem externalizar o pensamento do designer. Esta externalização permite a aprendizagem, pois possibilita que outras pessoas contribuam com informações e intuições a respeito do problema, que muitas vezes não fazem parte do seu conhecimento e experiência.

Para explanação do processo, este artigo irá utilizar a abordagem exposta por Jones (1978), 
O Processo de Desenvolvimento de Produtos de Moda ... no Design Thinking: um estudo de caso

o autor divide-o em três etapas consideradas essenciais e que são nomeadas de acordo com o pensamento utilizado em uma delas. As etapas são:

- Divergência: esta etapa visa ampliar o conhecimento que o designer possui sobre o problema a ser resolvido. São utilizados os conhecimentos explícitos do designer para obter informações sobre o contexto. Ele faz uma análise dos objetos existentes, ou seja, artefatos projetados para dar sustentação às práticas sociais vigentes.

- Transformação: esta é uma etapa de alto nível criativo e de elaboração mais amena, ela está dividida em duas outras etapas: a transformação divergente, onde utilizam-se métodos de investigação de ideias; e a transformação pura, que auxilia a elaboração de conceitos. Na transformação divergente o designer codifica os conhecimentos extraídos durante a divergência, com o objetivo de gerar o conhecimento explicitado. Neste momento ocorre um período de síntese, onde o designer organiza e interpreta os dados de maneira a dar forma a uma história ou conceito que norteará o projeto. Durante a transformação pura, o designer utiliza todo seu conhecimento para selecionar a melhor ideia e gerar um novo produto.

- Convergência: tem como objetivo selecionar uma única alternativa dentre todas possíveis. Nesta etapa o designer faz uso da linguagem escrita, visual, sonora para sintetizar, codificar e construir o protótipo e disseminar o novo conhecimento na organização.

Martin (2009) afirma que utilizar o design thinking dentro de uma organização é aplicar a principal ferramenta do designer para solucionar problemas de negócio. Esta ferramenta é o raciocínio abdutivo.

O raciocínio abdutivo, caracterizado por Pierce (1975), constitui um modo de inferência sobre o qual se estrutura o raciocínio criativo. Diferentemente dos raciocínios dedutivo e indutivo (que são modalidades de justificação e não de ampliação do conhecimento), o raciocínio abdutivo permite a formulação de novas hipóteses explicativas.

Conforme o próprio autor explica, a dedução prova algo que deve ser, a indução mostra algo que atualmente é operatório, já a abdução faz uma mera sugestão de algo que pode ser. Para apreender ou compreender os fenômenos, só a abdução pode funcionar como método. O raciocínio abdutivo são as hipóteses que formulamos antes da confirmação (ou negação) do caso. E essas hipóteses quando consideradas verdadeiras podem explicar o problema.

Martin (2009) diz que o pensamento abdutivo permite que design thinkers explorem possibilidades olhando para o futuro, enquanto ainda analisam oportunidades olhando para o passado.

\section{METODOLOGIA}

Este trabalho classifica-se como um estudo de caso. A pesquisa de campo realizada foi de caráter exploratório com uma abordagem qualitativa, ou seja, quando o pesquisador, que é parte integrante do objeto de estudo, utiliza suas experiências pessoais para compreensão do contexto.

Considerando que a pesquisadora é uma designer, utilizou-se como método a etnografia, uma modalidade da pesquisa científica, primordialmente de caráter qualitativo, no intuito de utilizar a habilidade de observação empática.

A pesquisa etnográfica tem como princípio a extração do conhecimento por meio da interação entre o discurso e o comportamento das pessoas, e as observações do pesquisador sobre cada detalhe que compõe o ambiente pesquisado.

Para uma melhor apreensão do objeto de estudo, utilizou-se uma tecnologia classificada como independente: que se refere a um caderno onde se registraram os acontecimentos, as impressões e as declarações do informante.

Inicialmente, este estudo foi realizado na sede da empresa, com a presença da responsável pelo processo de desenvolvimento de produto, que se dispôs a fornecer informações para a pesquisa.

Esta entrevista informal teve como objetivo extrair informações por meio de observação direta assim como, por meio de observação indireta realizada a partir da experiência que a pesquisadora possui dentro da empresa, foi realizada também uma busca de indícios visuais que poderiam auxiliar no levantamento de dados e permitir uma análise mais rica e detalhada das características da organização 
e do processo.

\section{Caracterização da empresa}

A indústria de confecção em estudo exerce suas atividades na cidade de Londrina, possui médio porte e atua no mercado há cerca de nove anos. Esta empresa deu início às suas atividades com a produção de enxovais para bebê e com o passar dos anos expandiu sua gama de produtos.

Atualmente, possui cinco marcas próprias, produzindo enxovais, bolsas, roupas para bebê e para o público infantil. Cada marca possui um público-alvo diferente e com necessidades distintas, permitindo assim que elas não concorram entre si.

Esta empresa possui uma administração familiar. Sua área de abrangência é o território nacional, por meio de representantes, principalmente nas regiões sul e sudeste. Ela possui atualmente 450 funcionários, sendo $70 \%$ mulheres e $30 \%$ homens que estão divididos em 11 setores: administrativo, desenvolvimento, modelagem, pilotagem, PCP, almoxarifado, corte, distribuição, costura, acabamento e expedição.

Em geral, as matérias-primas utilizadas pela empresa na confecção dos produtos são: malha, suedine, atoalhado, moleton, plush, tactel ${ }^{\circledR}$, sarja, jeans e tricoline; e alguns aviamentos como botões, fitas e strass.

Cabe considerar que a maior parte do processo produtivo ocorre internamente. No entanto, a estamparia, a lavanderia e parte das costuras são realizadas por empresas externas.

Observou-se que o processo de desenvolvimento dá-se da seguinte maneira: primeiramente é realizado um cronograma que norteará o desenvolvimento dos produtos, nele são delimitadas a data de lançamento da coleção, as datas limites para cada etapa do desenvolvimento e a quantidade de modelos que a coleção deverá ter. Em seguida o setor de desenvolvimento realiza pesquisas de tendências estéticas, pantones e matérias-primas; a partir dessa pesquisa são definidas as especificações da coleção, como o conceito e as referências a ser utilizadas para seu desenvolvimento. Mediante essas informações monta-se um briefing para os desenhistas, que farão as estampas corridas, locais e bordados das peças; este briefing é repassado a eles pelos designers de moda. Enquanto os desenhistas elaboram as estampas, os designers fazem uma avaliação da venda das coleções anteriores, com base num relatório de vendas elaborado pelo coordenador de produto. Com base nessas informações é feita a geração de alternativas dos modelos que entrarão na coleção, após isso são selecionadas as melhores alternativas e definidos quais modelos serão mantidos da coleção anterior. Com os modelos definidos é feito o dimensionamento e mix da coleção, que consistem em definir a proporção de tipos de peças que irão compor a coleção, já no dimensionamento são definidos quais tecidos, cores, aviamentos, acabamentos, estampas e bordados serão utilizados em cada peça. Em seguida inicia-se a etapa de elaboração do book, que é o conjunto dos modelos da coleção, nessa etapa são atribuídas referências (códigos) para cada modelo e este book é repassado para o setor de modelagem; simultaneamente inicia-se a etapa de aquisição de materiais, onde é feita a relação dos tecidos a serem utilizados e repassado ao técnico têxtil os tecidos que deverão ser pedidos.

Após a modelagem feita, esta é testada no setor de pilotagem, que confecciona a peça e identifica se haverá a necessidade de correções e ajustes. Em seguida, o setor de desenvolvimento inicia a confecção da ficha técnica dos produtos, com todas as especificações necessárias, nesta etapa também é calculado o custo dos produtos. Simultaneamente inicia-se a produção da pré-coleção, que consiste na confecção dos modelos nos tecidos e cores definidas, e com os bordados e estampas desenvolvidas.

Feito isso é realizada a análise da pré-coleção junto à alta direção, nesta etapa os produtos são aprovados ou reprovados. Se aprovados eles seguem por todas as etapas de produção (cadastro das peças no sistema, geração da ordem de produção e produção do mostruário) até a sua expedição. Caso seja reprovado, ele pode ser eliminado ou alterado, retornando ao setor de modelagem e seguindo as outras etapas já descritas. Enquanto os produtos encontram-se na fase de produção, o setor de desenvolvimento e o setor comercial elaboram a tabela de preço dos produtos e os materiais para os agentes de vendas, que consistem em uma apresentação da coleção e cartela de tecidos com combinação de cores dos produtos de cada marca. Para a elaboração desses materiais também conta- 
se com a participação do setor de marketing.

O fluxograma da Figura 4 apresenta o processo produtivo descrito de forma mais detalhada e nele estão identificados os setores que participam em cada etapa do processo.

Figura 4 - Mapeamento do processo da indústria de confecção.

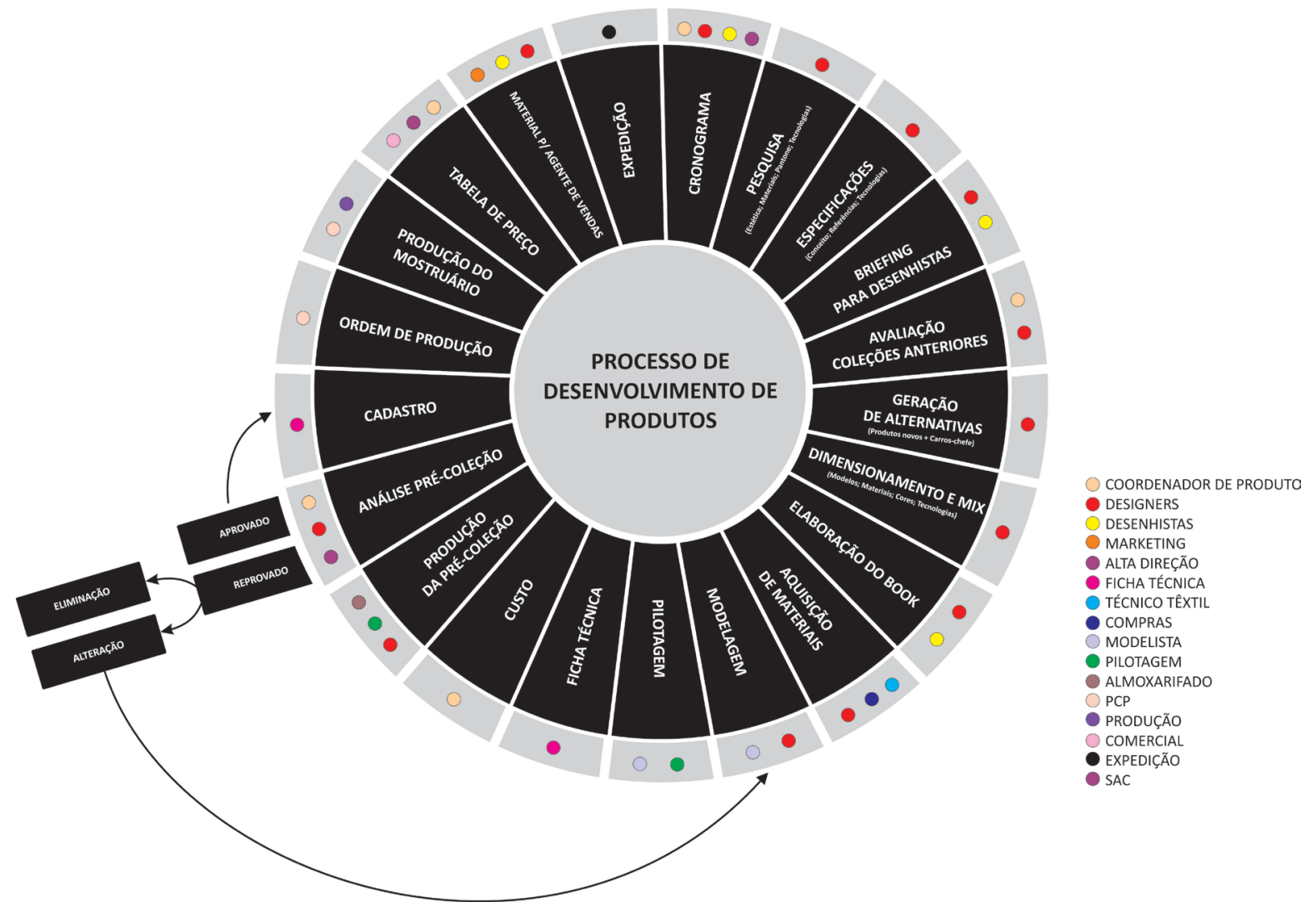

Fonte: Própria

É importante mencionar que nem sempre as etapas acontecem uma após a outra como descrito no mapeamento acima, muitas delas ocorrem simultaneamente, pois este é um processo bastante dinâmico e flexível. O mapeamento foi feito desta maneira para que o processo possa ser visualizado de maneira mais didática.

O setor analisado dentro da indústria aqui referenciada compreende o desenvolvimento dos produtos e analisando o mapeamento pode-se afirmar que as atividades realizadas nesse setor interferem nas demais etapas de toda a cadeia produtiva da empresa. Pode-se afirmar também que o setor é responsável por:

- $\quad$ pesquisas sobre tendências de mercado, matérias-primas, acabamentos,

- delimitações do projeto (definir conceito e referências),

- contato com fornecedores para aquisição de matérias-primas,

- coletar informações sobre coleções anteriores junto a parte comercial,

- desenvolver estampas e bordados,

- fazer o mix e dimensionamento da coleção (definir quantidades de modelos e suas composições)

- desenvolvimento de ficha-técnica

- acompanhamento da produção do mostruário,

- dar suporte aos outros setores solucionando dúvidas ao longo da produção.

\section{Proposta de intervenção}

Com base nos modelos apresentados anteriormente e com a utilização do design thinking, foi 
feita uma análise do mapeamento da indústria de confecção aqui apresentada e foram identificados pontos fortes e pontos fracos no processo de desenvolvimento.

Pontos fortes:

A equipe de desenvolvimento é composta por profissionais de diversas áreas, o que permite que trabalhem de maneira interdisciplinar.

Percebe-se que há a valorização e investimento na fase de pesquisa, que normalmente não acontece em indústrias de confecção.

É feita uma avaliação do custo dos produtos quanto a sua viabilidade produtiva e inserção no mercado.

Também é feita a análise de vendas das coleções anteriores, o que permite que a cada coleção os produtos se aperfeiçoem e satisfaçam ainda mais aos consumidores.

Pontos fracos:

Não existe um mapeamento do processo concreto e disponível a todos, apenas uma sequência de etapas que nem sempre é seguida conforme deveria.

Há perda de informação durante o processo, o que dá origem a retrabalhos.

Há desenvolvimento de produtos que nem sempre são utilizados, ocasionando perda de tempo e retrabalho para o setor de desenvolvimento. Por conta desses desenvolvimentos, são feitos pedidos de matérias-primas que nem sempre são utilizadas.

O setor de marketing não participa desde o início do processo de desenvolvimento, está inserido apenas no fim dele, o que dificulta a definição de estratégias de marketing para os produtos.

Para aperfeiçoar o processo de desenvolvimento de produtos e fortalecer os pontos fracos, a presente autora sugere algumas mudanças que garantirão maior eficiência ao processo. São elas:

- Inserção de 2 gates ao processo: pode-se observar que o processo já apresenta 1 gate (ponto de decisão) em sua estrutura, a análise da pré-coleção, porém faz-se necessário a criação de outros em 2 pontos críticos do processo. Os gates impedirão que os produtos sigam para as próximas etapas caso não estejam atendendo as especificações do início do processo. O primeiro gate deve ser inserido logo após a etapa de elaboração do book, e foi nomeado como pré-aprovação, nele o book da coleção será analisado junto à alta direção; se aprovado continuará o processo, caso contrário será eliminado ou sofrerá alteração e passará pelo gate novamente. A pré-aprovação terá o intuito de impedir que sejam feitos pedidos de matérias-primas e estas não sejam utilizadas. O segundo gate deve ser inserido antes da expedição dos produtos, e foi nomeado como conferência, neste gate o setor de ficha técnica deverá conferir as peças produzidas com sua respectiva ficha técnica e avaliar se as peças estão de acordo com o que foi estabelecido. Se aprovada a peça poderá ser usada como peça-piloto, caso contrário deverá ser refeita ou corrigido o erro, dependendo do tipo de inconformidade com a ficha técnica. A conferência tem o objetivo de avaliar as peças para que só sejam utilizadas peças-piloto que estejam atendendo rigorosamente as especificações estabelecidas na ficha técnica, evitando assim a divulgação de informações divergentes para a produção, isto é, uma informação na ficha técnica e outra diferente na peça-piloto.

- Elaboração de ficha técnica para uso do setor de modelagem e após pilotagem das peças atualização desta: como foi descrito no mapeamento acima o setor de modelagem recebe apenas o book da coleção para o desenvolvimento da modelagem e ele não há as especificações necessárias para tanto. A fim de evitar retrabalhos e desatualizações faz-se necessário o envio de uma ficha-técnica detalhada dos produtos ao setor de modelagem e após a pilotagem das peças esta ficha deverá ser atualizada caso tenha sido alterada alguma especificação descrita.

- Inserção da etapa de métodos e processos: após o cadastro dos produtos no sistema, fazse necessário o planejamento da produção do mostruário, para tanto deverá ser feito a relação de processos utilizados em cada peça para que se consiga obter um melhor planejamento da produção. Nesta etapa as dúvidas quanto aos novos produtos devem ser tiradas, promovendo assim mais autonomia à produção de como o produto deve ser produzido.

- Participação do setor de marketing desde o início do processo: para que se definam estratégias de marketing efetivas e em conformidade com os produtos, o setor deve participar de algumas etapas juntamente com o setor de desenvolvimento, etapas estas como: cronograma, pesquisa, pré-aprovação 
e análise da pré-coleção.

- Registro de lições aprendidas: para promover a melhoria contínua do processo, ao término de cada ciclo deve ser feito o registro de lições aprendidas. Este registro consiste em registrar ações que contribuíram e que dificultaram o processo, com essas informações em mãos devem ser feitas alterações no processo permitindo assim o aperfeiçoamento do mesmo a cada ciclo.

- Avaliação do desempenho dos produtos: durante a venda dos produtos deve-se fazer um relatório de trocas e reclamações e analisá-lo a fim de evitar que os mesmos erros aconteçam nas próximas coleções.

- Disponibilização do mapeamento a todos os envolvidos: como forma de sistematizar o processo e divulgar informações deve-se disponibilizar o novo mapeamento do processo a todos os setores envolvidos, assim como promover um treinamento para esclarecimento de dúvidas; isso contribuirá para o engajamento e o maior comprometimento dos participantes.

O fluxograma da figura 5 apresenta a proposta de intervenção inserida no mapeamento do processo de desenvolvimento de produtos da indústria de confecção estudada.

Figura 5 - Proposta de intervenção no processo de desenvolvimento de produtos da indústria de confecção.

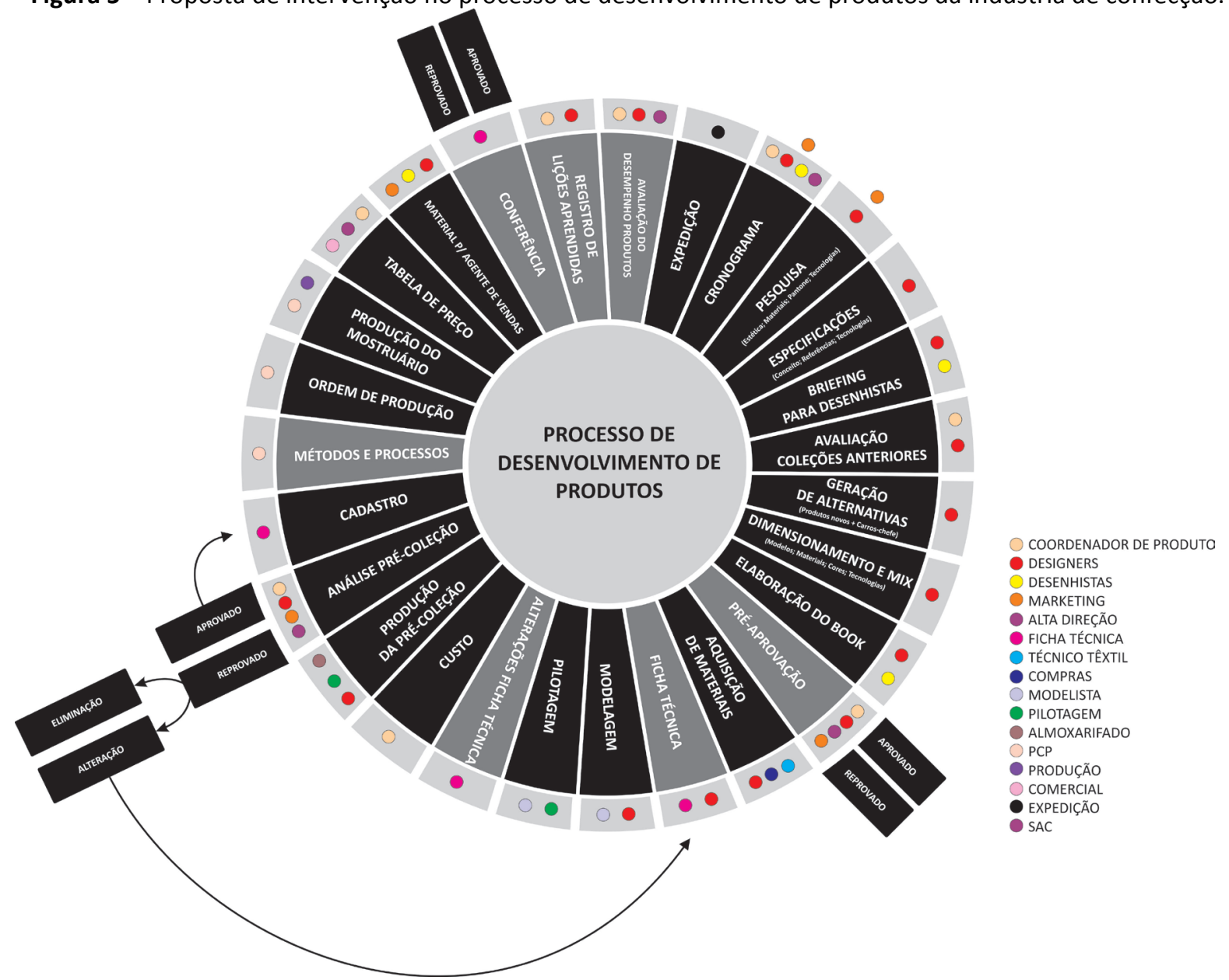

Fonte: Própria

Observando o mapeamento acima percebe-se a inserção dos gates e etapas propostas, essas modificações tornarão o processo um pouco mais longo porém garantirão maior qualidade e eficiência ao processo.

\section{CONCLUSÃO}

Por meio da análise feita pode-se afirmar que a maioria dos pontos fracos da empresa estudada concentra-se na ausência de sistematização do processo e no uso e divulgação das informações. Isto 
deve-se a rapidez que o setor requer entre o planejamento do produto e seu lançamento no mercado, no entanto a falta de planejamento acaba afetando os resultados no final do processo, ou seja, o produto final. Conforme afirma Jordan (2004), a maioria das empresas do segmento não possui um método definido para o PDP, os dados geralmente não são documentados e o foco do desenvolvimento está fortemente baseado na experiência da empresa.

Diante deste cenário e com base nas diretrizes do design thinking, torna-se possível colocar o ser humano no centro do processo, compreender melhor os usuários e envolver os integrantes do processo como colaboradores constantes. Para tanto foi realizada uma proposta de intervenção no processo de desenvolvimento, sugerindo melhorias com o intuito de fortalecer os pontos fracos identificados por meio da análise realizada. Porém estas modificações devem ser contínuas visto que estamos diante de um processo bastante complexo e dinâmico.

\section{REFERÊNCIAS}

BROWN, T. Design Thinking: uma metodologia poderosa para decretar o fim das velhas idéias (Elsevier, Eds.). p.249. Rio de Janeiro: Elsevier, 2010.

COOPER, Rachel, JUNGINGER, Sabine, LOCKWOOD, Thomas. Design Thinking and design management: A research and practice perspective. In LOCKWOOD, Thomas. Design thinking: Integrating innovation, customer experience, and brand value. New York: Allworth Press, 2006.

DEMARCHI, A. P. P. Gestão Estratégica de Design com a abordagem de design thinking: proposta de um Sistema de Produção do Conhecimento: 2010, 278 f. Tese (Doutorado em Engenharia e Gestão do Conhecimento) - Universidade Federal de Santa Catarina, Florianópolis, 2011.

DEMARCHI, Ana P., FORNASIER, Cleuza, MARTINS, Rosane. Processo de Gestão Estratégica de Design com a Abordagem de Design Thinking: Estudo de Caso Coasol. In: Design Management, 2012. Barcelona.

EMÍDIO, Lucimar de Fátima Bilmaia. A Gestão de Design como Ferramenta Estratégica para MPES do Vestuário de Moda - Dissertação de Mestrado. Bauru, 2006. 128f - Universidade Estadual Paulista (UNESP).

JORDAN, Marisa Beatriz Poletto. Processo de desenvolvimento de produto: um estudo para a indústria têxtil. Porto Alegre, 2004. Dissertação (Mestrado Profissional em Engenharia de Produção) Universidade Federal do Rio Grande do Sul.

LOCKWOOD, Thomas. Design thinking: Integrating innovation, customer experience, and brand value. New York: Allworth Press, 2009. 285 p.

MARTIN, R. The design of business: Why design thinking is the next competitive advantage. Boston: Harvard Bussiness Press, 2009.

MONTEMEZZO, Maria Celeste F. S. Diretrizes Metodológicas para o Projeto de Produtos de Moda no Âmbito Acadêmico - Dissertação de Mestrado. Bauru, 2003. 98f. Universidade Estadual Paulista (UNESP).

MONTEMEZZO, Maria Celeste F. S. A Síntese Visual como Ferramenta Projetual para a Concepção de Produtos de Moda. In: 4o Congresso Internacional de Pesquisa em Design, 4, 2007. Rio de Janeiro. Anais... Rio de Janeiro: ANPED, 2007.

PEIRCE, Charles Sanders. Semiótica e filosofia. São Paulo, Cultrix, Editora Universidade de São Paulo, 1975. 
O Processo de Desenvolvimento de Produtos de Moda ... no Design Thinking: um estudo de caso ROZENFELD, H. et. Al. Gestão do Desenvolvimento de Produtos - Uma referência para a melhoria do processo. Ed. Saraiva, 2006. 